Determining the Best of All Possible Worlds

Lloyd Strickland

Institute for Environment, Philosophy and Public Policy

Furness College

Lancaster University

Lancaster

LA1 4YG 


\section{Determining the Best of All Possible Worlds}

Up until about a decade ago, optimism, or the view that this is the best of all possible worlds, was the subject of a great deal of discussion in the philosophical literature. This has now largely ceased, apparently because a consensus view has been reached that the very concept of the best of all possible worlds can be shown to be incoherent by deploying the following simple argument: for any world that might be termed the best, there is always another which is better, therefore the concept of the best of all possible worlds is meaningless. ${ }^{1}$ To put the conclusion another way, the description "is the best of all possible worlds" can have no referent from among the full range of possible worlds.

The perceived strength of this argument, which is sometimes referred to as the No Best World argument, is such that even its adherents rarely use more than a sentence or two to introduce, develop, and deploy it. This is odd because the argument as presented above is in need of fleshing out, since as it stands it seems incomplete. Why is it that for any given world there is always another that is better? While many of the defenders of the argument do not explicitly say, some of them provide useful glimpses of the sort of answer they have in mind:

Presumably the goodness of...a world...will consist in part in it containing a finite or infinite number of conscious beings who will enjoy it. But if the enjoyment of the world by each is a valuable thing, surely a world with a few more conscious beings in it would be a yet more valuable world. ${ }^{2}$ 
Just as there is no greatest prime number, so perhaps there is no best of all possible worlds. Perhaps for any world you mention, replete with dancing girls and deliriously happy sentient creatures, there is an even better world, containing even more dancing girls and deliriously happy sentient creatures. ${ }^{3}$

Thus the reason why for any given world there is always another that is better is that if we examine the kind of goodness applicable to worlds, we find that it does not admit of a maximum degree.

It is evident that such an examination will have to be done a priori, and not just in the case of worldly goodness either. We do not determine that there is no greatest integer by getting a man or machine to write down all possible integers and asking them to let us know if they do or do not find one which could reasonably be described as the greatest. We simply ask if any contradiction would manifest itself if we kept adding to any given integer. In the case of integers it seems there is no manifest absurdity in the idea that for any positive integer there will always be another that is greater, and consequently there is a manifest absurdity in the notion of a greatest integer. Is a similar absurdity present in the notion of an upper limit to worldly goodness?

The consensus view seems to be that there is. Robert Elliot has argued that "it is plausible that...the range of values for possible worlds has no upper limit," though it would be difficult to endorse or criticise such a sweeping view without first ascertaining what the value or goodness of a world consists in. ${ }^{4}$ On this point there are two prevailing opinions. Some philosophers identify the quantity of happiness or enjoyment as the measure of the value or goodness of a world, while others suggest virtue. ${ }^{5}$ Do either of these admit of a maximum degree? 


\section{Happiness and Virtue}

It has been suggested that happiness is not a maximizable good, and so no matter how much happiness a world contains, it could always contain more. ${ }^{6}$ The two arguments commonly invoked to support this conclusion are that there is no logical maximum to how happy human beings or other creatures can be and that there is no logical limit to the number of happy beings that can exist in a world. A possible rejoinder to the first of these arguments is to say that, with us, it is the type of beings we are that limit our capacity for happiness. ${ }^{7}$ By extension, it seems reasonable to argue that other types of creature likewise have limits imposed on them by the kinds of beings they are. While the notion of species-set limits on happiness seems right, a weakness in this rejoinder is that it fails to eliminate the possibility of a limit to how far the species-set limits can go, and that there is an ultimate limit on happiness that cannot be exceeded by any possible type of creature, even if there are an infinity of them. However we do not need to go further into the question of whether there is a maximal degree of happiness, and possible creatures capable of attaining it, as the second argument mentioned above in support of the conclusion that there can be no maximally happy worlds seems to be unanswerable. It surely remains so whether we accept the idea of maximally happy creatures or not.

What, then, are we to say of the case for maximizing the virtue in a world? Again, it seems possible to argue that there is a limit to how virtuous any individual creature can be, this being defined by its life span. There are only so many virtuous deeds a creature can pack in to a finite lifetime, even if it was to spend all its available time performing virtuous deeds. ${ }^{8}$ But even if there is a limit to how virtuous any given 
individual can be, this does not mean that there is a corresponding limit to how much virtue a world can contain. As we saw in the preceding discussion on happiness, there are no limits on space. More maximally virtuous creatures could always be added to a world, thus boosting the sum total of virtue in that world ever upward.

\section{Three More Worldly Goods}

At this stage most philosophers suggest enough has been done to show the notion of the best possible world to be incoherent. But our failure to pick out a maximizable good can be explained just as well by the fact that we have so far been considering the wrong types of things as worldly goods. Certainly in the vast literature on the problem of evil we find an entirely different good mentioned time and again, namely creaturely free will. Indeed, the existence of free creatures is often considered to be such an overriding good that it outweighs all the evil that such creatures bring about by their frequent misdeeds. ${ }^{9}$ Could the number of free creatures be the measure of the goodness of a world? Although this would appear to be consistent with a lot of the thinking on the problem of evil over the last forty years, the snag is that, again, as there are no limits on space there is no obvious limit to the number of free creatures the universe could contain. If the goodness of possible worlds is measured by how many free creatures they contain, then there can be no best world.

It might be supposed that our aim of salvaging a coherent notion of the best of all possible worlds is now hopeless, as we have exhausted the most plausible candidates for worldly goods. It might further be supposed that, even if we can identify another candidate, we now have good inductive grounds for supposing that it is going to be as resistant to maximization as all the others. Both suppositions are wrong. An 
acquaintance with the historical literature on the problem of evil furnishes us with two further candidates for worldly goods, simplicity of natural laws and variety of phenomena. ${ }^{10}$ More promising still, both of these are seemingly maximizable. Let us take nomic simplicity first; how are we to understand the idea of the simple possible laws? The conception favored by both Malebranche and Leibniz is not, as might be supposed, that of the algebraically simplest laws, but of laws which are universal and uniform in nature. Considered this way, the idea of the simplest possible laws is perfectly coherent, as there is no contradiction in the idea of laws applying to all things in all places and times. In what follows, simplest laws will therefore be construed to be laws that are universal and uniform. Turning to variety, there again seems to be no contradiction in the notion of a world containing every compossible type of thing or, if we wish to take the Spinozistic route, every compossible thing. As long as there are no limits on space, which presumably there are not, maximal variety is achievable.

We have, at last, hit upon not one but two maximizable goods. It is worthwhile noting that variety and simplicity are not just relics of the golden age of theodicy; in fact simple laws have been worked into at least once recent theodicy. ${ }^{11}$ Moreover, theistic philosophers often consider them to be important in that the operation of universal and uniform laws enables free creatures to have a high degree of confidence about the outcomes of their actions, which is vital if free creatures are to be held responsible for what they do. ${ }^{12}$ Meanwhile the diversity of things has been credited with extending the range of choices available to free creatures and thus making free will more significant. ${ }^{13}$ Therefore simplicity and variety remain very plausible candidates for worldly goods even today. The drawback is that few contemporary philosophers would be prepared to accept that the goodness of a world is determined 
solely by how simple its laws are or by how much variety it contains. But why should we suppose that the goodness of a world is merely determined by its measure of one single good? Might not several goods combine to determine the measure of the goodness of a world? There is some appeal in this idea, as an insistence on monism requires the ruling out of four of the five candidates for worldly goods that we have identified, namely happiness, virtue, free creatures, nomic simplicity, and variety of phenomena, and this hardly seems defensible given that each candidate appears to bring some value to a world. What this suggests is that the goodness of a world might not be determined by a single type of good, as proponents of the No Best World argument typically suppose, but by a combination of two or more types of good. Prima facie such a suggestion would seem to fall victim to the same problem as before, namely that maximization is no more possible with two goods than it is with one. Of course maximization is possible if we take the goodness of a world to be determined wholly by variety and nomic simplicity, as both can be maximized. But with any other combination of the five possible goods we have identified, maximization will not be possible and, consequently, it will be impossible for there to be a best among an infinity of possible worlds. If the goodness of a world is determined by at least two goods, and at least one of these goods is inherently nonmaximizable, then it would always be possible to include more of that good in a world irrespective of whether the other goods can be maximized.

However a significant assumption made here is that, if there is more than one particular type of good that determines the goodness of a world, then the goods will be mutually compatible. This is not a reasonable assumption to make, since some goods could be in tension or conflict with one another, such that the more there is of one type of good the less there can be of another. Where there is such tension, and 
goods are in opposition, so to speak, we find that instead of looking for a world which contains the maximum of one or more type of good, we are searching for one that possesses the optimal trade-off between at least two types of conflicting good. We should be clear that this represents a fundamental shift in our focus, as the notion of maximization is altogether different from that of optimization, and it would be worthwhile taking the time to clarify the distinction.

\section{Optimization and Maximization}

Maximization is the process whereby the greatest possible degree of a variable or parameter is realised. Optimization also involves the realisation of a maximum, but in circumstances where there are two or more variables or parameters, and there is an inbuilt tension or conflict between these objectives. In such cases, the best result is not typically obtained by maximizing one of the variables or parameters, but by seeking a compromise between them. Optimization is thus a maximization of the functions between variables or parameters. This abstract characterization needs fleshing out. Fortunately for our purposes, optimization is not just a concept familiar in the rarefied world of mathematics, it is also common in economics, biology and engineering, as well as other disciplines drawing on mathematical reasoning, and these afford us many examples of optimization at work. For instance, economists have discovered that there is a tension between the government objectives of low inflation and low unemployment, and they represent this graphically by the Philips curve, which plots an inverse relationship between the rates of inflation and unemployment. A similar relationship is observed by biologists between litter size and size of offspring, namely the greater the one, the less of the other. In aircraft design several design parameters 
compete, such as weight of the craft, fuel efficiency and payload. Increasing one of these design parameters invariably leads to a decrease in the others, making it necessary to trade them off against each other. What this example brings out is the element of constraint that conflicting variables impose on a designer. In aircraft design these are causal conflicts and therefore causal constraints, as their existence depends to a large extent on our current level of technical know-how and what is possible given the laws of nature that we have. Causal conflicts such as these, and the constraints that arise from them, would obviously not frustrate an omnipotent God. But the sort of conflicts we are supposing to hold between worldly goods are not causal in nature, but logical, and they therefore bring with them logical constraints on what even God can achieve when creating a world. Any appeal that omnipotence is not bound by the constraints imposed by conflicting goods is therefore just wasted breath, as omnipotence is typically taken to have to work within the boundaries of logic rather than outside them.

Let us now go a little further into the idea of a conflict obtaining between two or more worldly goods. Suppose a simplified scenario of two goods that are inversely related, such that the more there is of one good the less there can be of another. Would it be better to have a lot of the first good and a little of the other, or a little of the first good and a lot of the other? In cases such as this there is a recognised mathematical procedure for ascertaining the optimal result, known as the calculus of variations. This utilises differential equations to determine the optimal condition for a relationship between two or more variables such as our conflicting goods. What holds us back from wheeling in the mathematicians is the need to give accurate and detailed information about the goods being traded off. For instance, we know that our conflicting goods will have an inverse relationship, but is this a straightforward 
inverse relationship or a more complicated one? Do we assume that both goods are equally weighted, or that one is of greater value than the other? Hence not only do we need to know what the goods in question are, but also the nature of the relation between them and their respective value as determined by the objective standards for world making. Without the required information our tool for determining the optimal trade-off cannot be brought into play, which means that the optimal balance of goods must remain a mystery. But for our purposes it is not necessary to actually determine the optimal trade-off of conflicting goods, only to recognise that theoretically it can be done and that there is a determinate point in the relationship between opposing goods that marks a trade-off that cannot be bettered. Other trade-offs return inferior results, and hence inferior worlds, thanks to the law of marginal returns. In the possible world exemplifying the optimal trade-off between two or more conflicting goods, we therefore have a genuine best of all possible worlds.

\section{Incommensurability and Incomparability}

Before identifying which goods are in conflict, we need to ensure that optimizing them will even be possible. Indeed some readers are likely to argue that it will not be possible, on the grounds that, as we are positing conflicting goods, these goods will in all likelihood be incommensurable. ${ }^{14}$ To put this another way, the values of the goods in conflict seemingly cannot be converted to a common measure and ranked on a single scale. This in turn is said to entail that many worlds will be incomparable with each other, because there will be no way to rationally determine whether, in terms of value, one will be better, worse or much the same as another. For instance, if one world has one hundred units of a particular good and five of a different good, and 
another world has five units of the first good and one hundred units of the other, how can they be appropriately compared? Unless the values of the two goods can be converted to a common measure it seems that they cannot be compared, and if that is right then it will be impossible, even in principle, to determine which of the two possible worlds is best. Since many other possible worlds will be no less comparable with each other, our hope of finding a coherent notion of the best of all possible worlds will lie in ruins. The objection from incommensurability could thus hardly be more serious

By way of response we might appeal to the old chestnut of epistemic constraints, namely that problems of incommensurability and incomparability might only be problems in the human sphere, and that God, being omniscient, can see in an instant the means of resolving them even if these means happen to elude us. There is a lot of mileage in this response. When the incommensurabilist points out the difficulty in ranking different degrees of different goods he is assuming that appearance and reality match up, so that goods that seem to us to be incommensurable really are incommensurable. But we would be justified in asking the incommensurabilist for a reason to rule out categorically even the barest possibility that one good might be commensurate with another good, and also justified in insisting that this reason not hinge merely on how things might appear. This demand should not be mistaken for a weak attempt to evade the issue either, as matters pertaining to world creation are very dimly understood by human reason, if they are even understood at all, so we must be wary of projecting problems from the human sphere onto larger theatres. In any case, even if the incommensurabilist can provide us with proof of the incommensurability of goods, incommensurables are not always incomparable. For example, the first recorded case of incommensurability was that uncovered by the 
Pythagoreans, who could discern no common unit that would express the side of a square and its diagonal. Despite this incommensurability, the two lengths are comparable and can be mathematically proved so. Other examples of incommensurability can be dealt with using what Ruth Chang has called "nominalnotable comparisons," which are worth illustrating. ${ }^{15}$

Consider the two worlds we discussed earlier. In terms of goodness the first world has one hundred units of a particular good and five units of another good, while the second world has five units of the first good and one hundred units of the other. Let us now consider a further world, which has five units of the first good and five of the other. In Chang's terminology, the first two worlds described are deemed notable bearers of value because they each possess a very high overall level of value, whereas the third world is deemed a nominal bearer of value as it possesses a very low overall level of value. Although the introduction of the third world may not shake our conviction that the first two worlds are incomparable, we can nevertheless see that the third world is comparable to both of the others. Moreover, a comparison will show that the third world is not just inferior to the first and second worlds in terms of value, but considerably inferior. At this point let us consider a fourth world that is better than the third world but only by virtue of its possessing the smallest possible extra amount of the second of the two goods. This fourth world is obviously comparable to the second world, but is it also comparable to the first world? It seems very plausible to suppose that it is, as the fourth world is scarcely a better nominal bearer of value than the third world, and the third world as we know is certainly comparable to the first world. If we accept that comparability holds between the first and fourth worlds, as seems reasonable, then we would also have to accept that it holds between the first world and a fifth world, which is better than the fourth but again only by virtue of its 
containing the smallest possible extra amount of the second of the two goods. In other words, we are forced to concede the values of different kinds of goods are not inherently incomparable at all. ${ }^{16}$ This does not necessarily mean that we can easily decide which of the first and second worlds is better, and it is possible that we could never work it out. But then again we do not have to; the only being who needs to know how to rationally discriminate between possible worlds is he who is looking to create one. For our purposes it matters only that worlds possessing different values of conflicting goods can be compared, as this alone is enough to guarantee a coherent notion of the best of all possible worlds.

\section{The Conflict of Worldly Goods}

Let us consider whether any of the five goods identified earlier are in conflict as described above. For our purposes it does not matter which of our five candidates for worldly goods are actually worldly goods. In order to develop a coherent notion of the best of all possible worlds it will be sufficient to show that tensions are present between some of the most plausible candidates for worldly goods, and therefore if any of these candidates turn out to be genuine worldly goods then they will need to be optimized.

We can discern three pairs of goods that are in tension, namely simplicity and happiness, variety and happiness, and virtue and happiness. First, there is a conflict between nomic simplicity and human happiness, since if the laws of the world were more flexible and therefore not so uniform and universal, then much of what typically makes men unhappy need never occur. But a simple and regular network of laws is not conducive to widespread happiness, principally because of its rigidity. ${ }^{17}$ 
A second conflict is found between happiness and the variety of phenomena in a world. Plotinus, who believed that our world does feature maximal variety, noted that in a world of diversity things simply get in the way of each other, leading to a "war without rest, without truce" among things. ${ }^{18}$ People are involved in the war no less than any other creature; consider how much human unhappiness has been caused by the range of bacteria, viruses, parasites and other organisms, large and small. It is the nature, the very being of certain creatures to cause harm to others, because part of what it is to be those creatures is to act in ways which bring about harm to others, and they cannot be what they are without bringing about that harm. Some aspects of a varied world are thus of necessity directly opposed to human happiness. It could be argued that, with a little careful planning, this need not actually cause any human unhappiness, for instance if every type of creature was allocated its own planet away from humans. This arrangement, it might be said, would guarantee maximal diversity of things and yet also ensure that no type of creature would ever cause suffering to mankind. But there are two problems with this suggestion. First, if the variety of things is, as we suggested earlier, a good on account of it increasing the range of choices available to free creatures, it follows that free creatures and other things should not be kept apart. Second, if creatures were kept apart in the way described above, the arrangement would lead to either mass cannibalism or mass starvation on almost every planet. Suffering and unhappiness would therefore still be widespread among other creatures even if not among our own species.

The final conflicting pair of goods is virtue and happiness. We do not need to hold a form of Kantian ethics to recognise a tension between these two, because in the normal usage of the term, and certainly in the theistic context which is assumed in this paper, virtue is taken to involve, at least in part, the overcoming of an inclination or 
temptation to act solely for personal benefit. To put it another way, virtue often involves selflessness and sacrifice, as is clear from examples such as charity, chastity, and courage. In order to be charitable, chaste, or courageous, a person has to put their own desires to one side and pursue a course that is often not the most pleasant of those on offer. Moreover, some virtues logically require evils: courage requires hardship, for instance, and generosity requires need, and as hardship and need are clear sources of unhappiness, it is but a short step to the realisation that in order for anyone to be courageous and generous there must be others who are experiencing unhappiness. Virtue can thus be said to be in tension with happiness for two reasons: the practice of virtue requires sacrifices to be made, which impacts on the happiness of the person who makes them, and in order for some virtues to be practiced at all there must also be others already experiencing suffering and unhappiness.

Although it is possible that there might be other tensions between the five possible goods identified earlier, we shall henceforth assume that the only conflicts between them are those outlined above. As it stands then, out of our five possible goods, all of the various conflicts between them involve happiness. If we were to assume for a moment that happiness is a worldly good, we can see that there are fifteen possible combinations it can make with the other four goods. For example, happiness can be combined with virtue, with simplicity, with free creatures and with diversity; happiness can also be combined with pairings of other goods, such as with virtue and simplicity, with virtue and free creatures, with virtue and variety, with simplicity and free creatures, with variety and free creatures, or with variety and simplicity; happiness can also be combined with any three of the other four possible goods, such as with virtue, simplicity, and free creatures, with virtue, simplicity, and variety, with virtue, free creatures, and variety, or with simplicity, free creatures, and diversity; 
lastly, happiness can be combined with all four of the other possible goods. It is notable that out of these various combinations there is only one permutation, namely happiness and free creatures, that cannot be optimized, since there is no conflict between them. All the other combinations are optimizable combinations because happiness conflicts with virtue, simplicity and variety. What this means is that if happiness is a genuine worldly good, which is plausible to suppose, and one or more of virtue, variety and nomic simplicity is also a worldly good, as again is plausible to suppose, then because of the various tensions that exist between these goods, tradeoffs will be necessary to obtain the optimal balance between them, the balance that cannot be bettered by the further addition or subtraction of any of the goods. Only if we were to say that happiness and the number of free creatures wholly determine the goodness of a world would we be excused from admitting that there can be a best of all possible worlds. If we accept that the goodness of a world is determined by any other combination of goods then we are not so excused, and must allow that there is a best of all possible worlds, even if we wish to deny that this is it.

The question that emerges from this is, which of the fourteen optimizable combination of goods is most likely to be the combination that determines the goodness of worlds? No attempt shall be made to answer that question here, nor the further question of where the optimal balance between conflicting goods might lie. ${ }^{19}$

\section{Notes}


${ }^{1}$. See Charles Journet, The Meaning of Evil (London: Geoffrey Chapman, 1963), pp. 117-118; H. J. McCloskey, God and Evil (The Hague: Martinus Nijihoff, 1974), p. 82; Alvin Plantinga, God, Freedom and Evil (Grand Rapids, Michigan: William B. Eerdmans Publishing Company, 1974), p. 61; George Schlesinger, Religion and Scientific Method (Dordrecht: D. Reidel Publishing Company, 1977), pp. 65, 72; Bruce Reichenbach, "Must God Create the Best Possible World?," International Philosophical Quarterly 19 (1979), p. 208; R. K. Perkins Jr, “McHarry’s Theodicy: A Reply," Analysis 40 (1980), p. 171; Peter Forrest, “The Problem of Evil: Two Neglected Defences," Sophia 20 (1981), p. 52; William Hasker, “Must God Do His Best?," International Journal for Philosophy of Religion 16 (1984), p. 213; Richard Swinburne, The Existence of God, 2nd ed. (Oxford: Oxford University Press, 1991), pp. 113-114; Philip L. Quinn, “God, Moral Perfection, and Possible Worlds," in Michael L. Peterson, ed., The Problem of Evil (Notre Dame, Indiana: University of Notre Dame Press, 1992), p. 294; Robert Elliot, "Divine Perfection, Axiology and the No Best World Defence," Religious Studies 29 (1993), p. 533; Daniel Howard-Snyder \& Frances Howard-Snyder, "How an Unsurpassable Being Can Create a Surpassable World," Faith and Philosophy 11 (1994), p. 260.

2. Swinburne, op cit., p. 114.

3. Plantinga, op. cit., p. 61 .

${ }^{4}$. Elliot, op. cit., p. 533; cf Perkins Jr, op. cit., p. 171.

${ }^{5}$. For happiness see Swinburne, op. cit., p. 114; George Schlesinger, New Perspectives on Old-Time Religion (Oxford: Oxford University Press, 1988), p. 55. For virtue see Quinn, op. cit., p. 293; Osmond G. Ramberan, “God, Evil and the Idea of a Perfect World,” Modern Schoolman 53 (1976), p. 392.

${ }^{6}$. See Reichenbach, op. cit., p. 208; Jay Rosenberg, “The Problem of Evil Revisited: A Reply to Schlesinger," Journal of Value Inquiry 4 (1970), pp. 213-214; Schlesinger, Religion and Scientific Method, p. 62; Peter Geach, The Virtues (Cambridge, England: Cambridge University Press, 1977), p. 98; Swinburne, op. cit., p. 114. 
${ }^{7}$. See Stephen Grover, "Satisfied Pigs and Dissatisfied Philosophers: Schlesinger on the Problem of Evil," Philosophical Investigations 16 (1993), p. 222.

${ }^{8}$. For an alternative view see John McTaggart Ellis McTaggart, The Nature of Existence Vol. II (Cambridge, England: Cambridge University Press, 1927), pp. 414-415.

9. See John Mackie, The Miracle of Theism (Oxford: Oxford University Press, 1982), p. 155; Richard Swinburne, Providence and the Problem of Evil (Oxford: Oxford University Press, 1998), p. 107.

${ }^{10}$. For simplicity see G. W. Leibniz, Theodicy, trans. E. M. Huggard, ed. Austin Farrer (Chicago: Open Court, 1990), p. 257; Nicolas Malebranche, Dialogues on Metaphysics and on Religion, trans. David Scott (Cambridge, England: Cambridge University Press, 1997), p. 163. For variety see Aquinas, Selected Philosophical Writings, trans. and ed. Timothy McDermott (Oxford: Oxford University Press. 1993), p. 271; Leibniz, op. cit., p. 198; G. W. Leibniz, Philosophical Writings, trans. and ed. G. H. R. Parkinson (London: Everyman, 1973), p. 146.

${ }^{11}$. See Bruce Reichenbach, "Natural Evils and Natural Laws: A Theodicy for Natural Evils," International Philosophical Quarterly 16 (1976), pp. $187 f$.

12. See Ninian Smart, Philosophers and Religious Truth (London: SCM Press, 1964), p. 154; Ramberan, op. cit., p. 381; Swinburne, Providence and the Problem of Evil, pp. $179 \mathrm{ff}$.

13. See John Hick, Evil and the God of Love, 2nd ed. (London: Macmillan, 1985), p. 309; Swinburne, Providence and the Problem of Evil, pp. 166f.

${ }^{14}$. See Stephen Grover, "Incommensurability and the Best of All Possible Worlds," The Monist 81 (1998), pp. 662-664.

${ }^{15}$. Chang, op. cit., p. 14.

${ }^{16}$. See Ruth Chang, "Introduction," in Ruth Chang, ed., Incommensurability, Incomparability, and Practical Reason (Cambridge, Mass.: Harvard University Press, 1997), pp. 14-17, and Donald Regan, "Value, Comparability, and Choice," in Ruth Chang, ed., Incommensurability, Incomparability, and Practical Reason (Cambridge Mass.: Harvard University Press, 1997), pp. 
134-136.

${ }^{17}$. See David Hume, Dialogues Concerning Natural Religion, ed. Stanley Tweyman (London: Routledge, 1991), pp. 164-165; Swinburne, Providence and the Problem of Evil, pp. 188-189; Daise Radner \& Michael Radner, “Optimality in Biology: Pangloss or Leibniz?,” The Monist 81 (1998), p. 682 .

${ }^{18}$. Plotinus, Enneads, trans. Stephen Mackenna (London: Penguin, 1991), III.2.15, p. 150.

19. My thanks to Vernon Pratt, Patrick Sherry and Chakravarthi Ram-Prasad for their comments and suggestions on an earlier draft of this paper. 